Christopher P. Reinders Folmer*, Peter Mascini and Joost M. Leunissen

\title{
Rethinking Apology in Tort Litigation Deficiencies in Comprehensiveness Undermine Remedial Effectiveness
}

https://doi.org/10.1515/rle-2018-0042

\begin{abstract}
Apologies are assumed to be an effective pathway to the restoration of victims of torts. Accordingly, initiatives to facilitate their provision in legal contexts are currently being advocated. A crucial question, however, is whether the apologies that perpetrators provide in these contexts may live up to such expectations. Do perpetrators' apologies in response to torts convey the content that victims desire, and how may this affect their remedial effectiveness? The present research examined what content victims desire, and perpetrators provide in apology in response to personal injury incidents. In two studies, we demonstrate that (a) perpetrators provide less comprehensive apologies than victims desire, and (b) their apologies thereby are less effective at restoring them. These differences were explained by their differing perception of torts, such that perpetrators regard their transgressions as less severe and intentional, and themselves as less blameworthy than victims do, and consequently offer less comprehensive apologies than victims desire. Therefore, subjectiveness in victims' and perpetrators' perception of torts may undermine the remedial effectiveness of legal apology.
\end{abstract}

Keywords: apology, bias, tort law, personal injury, forgiveness, restorative justice

\section{Introduction}

Legal perspectives have increasingly recognized that apologies can make an important contribution to victims' restoration after torts, and to the resolution of such

\footnotetext{
*Corresponding author: Christopher P. Reinders Folmer, Department of Private Law, Erasmus School of Law, Erasmus University Rotterdam, Burgemeester Oudlaan 50, Rotterdam 3062 PA, The Netherlands, E-mail: reindersfolmer@law.eur.nl

https://orcid.org/0000-0003-1340-2300

Peter Mascini, Erasmus School of Law, Erasmus University Rotterdam, The Netherlands, E-mail: mascini@essb.eur.nl

Joost M. Leunissen, School of Social Sciences, Nottingham Trent University, Nottingham, UK, E-mail: joost.leunissen@ntu.ac.uk
}

Ә Open Access. (c) 2019 Reinders Folmer et al., published by De Gruyter. (c))BY-NC-ND This work is licensed under the Creative Commons Attribution-NonCommercial-NoDerivatives 4.0 License. 
incidents (Allan and Carroll, 2017; Berryman, 2017; Carroll, 2013; Cohen, 1999; Kleefeld, 2017; Latif, 2001; Shuman, 2000; Vines, 2015). Apologies may constitute an important means of nonmonetary relief for victims of torts (Van Dijck, 2018a, 2018b). By mollifying the victim, apologies may also contribute to settlement (Robbennolt, 2003, 2006). Moreover, apologizing may also be beneficial to perpetrators, as doing so may reduce feelings of guilt and evoke forgiveness (Fisher and Exline, 2010; Riek, 2010). But in spite of these benefits, legal practice reveals that perpetrators often are reluctant to apologize. Their reluctance is particularly rooted in concerns that apologies will be interpreted as an admission of liability (e. g. Kleefeld, 2017; Latif, 2001; Van Dijck, 2018b). In response, legal systems increasingly implement provisions to facilitate apology (e.g. apology protection laws, see Kleefeld, 2017; court-imposed apologies, see White, 2005), to thereby unlock their anticipated benefits for the restoration of victims and the resolution of torts (Berryman, 2017; Carroll, 2013; Kleefeld, 2017; Latif, 2001; Wagatsuma and Rosett, 1986).

But while such initiatives certainly may facilitate perpetrators' provision of apologies, a crucial question is to what extent these may amount to satisfactory apologies, which effectively evoke the remedial outcomes with which such remedies have been credited. Legal perspectives on apology have increasingly recognized that apologies may differ in content, and may frequently fall short of being comprehensive (e. g. Carroll et al., 2017; Day and Ross, 2011; Dhami, 2012, 2017; Levi, 1997). Psychological research has suggested, however, that more comprehensive apologies (i. e. apologies containing a greater number of elements) may be more effective (Lewicki et al., 2016; Scher and Darley, 1997; Schumann, 2014), and that the inclusion or omission of particular elements may influence this (Lazare, 2004; Kirchhoff et al., 2012). As such, to understand their remedial value in tort litigation, a crucial question is to what extent the comprehensiveness that perpetrators offer in apology may live up to that which victims desire, and how this may influence the effectiveness of their apologies. It is these questions that the present research aims to illuminate.

In the present contribution, we present two studies that examine the content that victims desire, and perpetrators provide in apology in response to torts, and compare their comprehensiveness. Moreover, we examine how the resulting differences may impact the remedial effectiveness of apologies. We relate these processes to victims' and perpetrators' contrasting interpretation of torts, in terms of their differing perceptions of severity, intentionality, and responsibility (Adams and Inesi, 2016; Baumeister et al., 1990; Loewenstein et al., 1993; Malle, 2006). We test this framework in context of personal injury incidents, as the domain of tort law that is at the forefront of the legal debate on apology (Abel, 2006; Vines, 2015), and where their remedial potential has previously been demonstrated (Robbennolt, 2003, 2006). 


\section{The remedial potential of apologies}

The remedial value of apologies lies in their potential for restoring the emotional harm that victims may experience in response to torts. In recent years, legal perspectives have increasingly recognized that victims' needs in response to torts may often extend beyond the monetary remedies that the legal system provides. Indeed, empirical study of claimants' litigation aims has revealed a range of "extra-legal objectives of principle" that victims may pursue in response to torts, including admission of wrongdoing, acknowledgement of harm, prevention, punishment, and retribution (Relis, 2007; also see Carroll and Witzleb, 2011; Van Dijck, 2018a). Such observations mirror insights from psychology, which demonstrate that victims' needs following transgressions extend beyond distributive concerns to include relational needs for fair treatment, recognition, and respect (Okimoto and Tyler, 2007). But while such needs may be prominent in response to torts, they may not be restored as effectively by the monetary remedies of tort litigation, which are limited in their capacity for conveying relational meaning (Abel, 2006; Hulst and Akkermans, 2011; Okimoto and Tyler, 2007). It is in this function that legal perspectives advocate apologies: apologies may convey remorse (e. g. "I am sorry"), acceptance of responsibility (e. g. "it was my fault"), acknowledgement of the victim's harm (e.g. "I know that I hurt you"), and sympathy (e. g. "you must feel terrible), which directly address needs relating to blame and recognition. Moreover, apologies may address needs for punishment or retribution by symbolically humbling the perpetrator (Tavuchis, 1991), or by including explicit offers of repair ("please let me make it up to you") or promises of forbearance ("I will make sure this never happens again"). In these ways, apologies have the potential to address non-monetary needs that are not resolved by monetary compensation. Accordingly, apologies are assumed to enhance victims' restoration and to promote settlement, by evoking a more conciliatory stance that reduces vengefulness and promotes forgiveness (Cohen, 1999; Robbennolt, 2003, 2006; Vines, 2015).

An important caveat to this assumption, however, is that in order to fulfill this remedial potential, the apologies that perpetrators provide must live up to what victims desire in apology. When considering findings from both legal and psychological research, questions may be raised over the extent to which this will be the case. To begin with, psychological research indicates that the remedial effectiveness of apologies is greater when apologies are more comprehensive, and include a greater number of elements (e. g. remorse, acceptance of responsibility, acknowledgement of harm etc.; Lewicki et al., 2016; Scher and Darley, 1997; Schumann, 2014). However, insights from law and psychology suggest that perpetrators' apologies often fall short of being comprehensive 
(Carroll et al., 2017; Dhami, 2012, 2017; Schumann, 2014; Taft, 2005). This juxtaposition raises the question to what extent the content of perpetrators' apologies thereby may differ from that which victims desire, and how this may impact their remedial effectiveness in the resolution of torts. While extant research has not yet examined these questions, legal research does provide some indications that this content may not correspond. For example, in the domain of criminal law, research demonstrates that victims of juvenile crime displayed favorable beliefs about the potential merit of apology, but less favorable responses to apologies actually made by perpetrators, citing missing or mismatched content (e.g. failure to accept responsibility, making excuses) as one important reason (Choi and Severson, 2009) ${ }^{1}$. This conclusion mirrors insights from psychological research, which shows that perpetrators may avoid content that is more threatening to the self (including remorse, acceptance of responsibility, and offers of repair, Schumann, 2014), and that victims may experience perpetrators' apologies to be less satisfying than they anticipated them to be (De Cremer et al., 2011). Together, such findings seem to imply that the comprehensiveness of perpetrators' apologies in response to torts may not match the level that victims desire - with detrimental effects for their remedial value.

\section{Victim-perpetrator perspectives on apology comprehensiveness: The role of subjective perception of torts}

Why would perpetrators offer less comprehensive apologies in response to torts than victims desire? Some scholars have particularly understood reluctance to apologize in terms of strategic considerations. According to them, perpetrators may avoid apology (or particular elements in apology, such as accepting responsibility) in order to avoid admitting liability (e. g. Kleefeld, 2017; Latif, 2001; Van Dijck, 2018b). It is such considerations that have inspired legal provisions to facilitate apology, which aim to assuage such concerns (e. g. Kleefeld, 2017).

The present research, however, will investigate to what extent contrasting perceptions of torts contribute to differences between victims' and perpetrators' perspectives on apology, thereby leaving open the possibility that both strategic

1 Note that this finding reflects victims' self-reported experiences in qualitative research; the study did not examine the content of perpetrators' apologies, or that desired by victims. 
and non-strategic reasons contribute to a potential apology gap. This explanation is based on another strand of research which has established that people's perceptions of what remedies are appropriate in response to a transgression are critically shaped by its features: people regard more extensive remedies to be appropriate the greater its severity, its intentionality, and the perpetrator's responsibility for it (e.g. Darley and Pitman, 2003; Felson and Tedeschi, 1993; Leunissen et al., 2013; Robbennolt, 2003). Importantly, however, disputants' perceptions of such features are not equivalent, but rather may differ (Adams and Inesi, 2016; Baumeister et al., 1990). This reasoning implies that victims and perpetrators consequently may also hold differing perspectives on the restoration of their disputes, in terms of the remedies that they regard as suitable.

This prediction is rooted in psychological research on conflict and reconciliation. Such research demonstrates that relative to perpetrators, victims perceive transgressions as more severe and less comprehensible, and attribute greater responsibility for them to the perpetrator (Baumeister et al., 1990; Kearns and Fincham, 2005; Stillwell and Baumeister, 1997). Indeed, Adams and Inesi (2016) suggest this to represent a "fundamental asymmetry" between how victims and perpetrators interpret transgressions. This discrepancy has firstly been suggested to reflect information differences. Victims and perpetrators differ in their access to crucial information for making such interpretations - such as the circumstances that contributed to the transgression, or the nature of its consequences (Malle, 2006). Accordingly, they may come to differing conclusions on the nature of the harm, and the role of personal and situational factors in its emergence. Secondly, such discrepancies have been suggested to reflect self-serving bias, such that actors interpret transgressions in ways that are favorable to the self (i. e. by under- or overstating harm or personal responsibility, Kearns and Fincham, 2005). In line with this explanation, contrasting perceptions have been shown to persist when transgression features are manipulated, and therefore are clear instead of ambiguous (e.g. intentionality, see Leunissen et al., 2013). In either case, the outcome of these processes is identical: that disputants' perceptions of features that are key predictors of apology (Darley and Pitman, 2003; Felson and Tedeschi, 1993; Leunissen et al., 2013) will be miscalibrated. Simply put: if perpetrators perceive transgressions to be less severe, intentional, and responsible to themselves than victims do, they consequently may also perceive a lower need for apology, and apologize less comprehensively, than what victims would desire. Accordingly, perceptual differences may undermine the comprehensiveness of apology, and thereby their remedial value in the resolution of torts. 


\section{Theoretical model, research overview and hypotheses}

Our theoretical framework (Figure 1(a)) assumes that relative to victims $($ role $=0$ ), perpetrators (role $=1$ ) will perceive torts as less severe, intentional, and will attribute lower responsibility for their occurrence to themselves (path a, negative association). Greater perceptions of severity, intentionality, and responsibility are expected to increase perceptions of the need for apology, and the comprehensiveness of apology (path c, negative association). Accordingly, our model assumes a mediating relationship, whereby due to their differing perceptions of torts, perpetrators will perceive a lower need for apology, and will provide less comprehensive apologies than victims desire. The resulting difference in comprehensiveness will reduce the remedial effectiveness of the apology (Figure 1(b), path d, negative association).

(a)

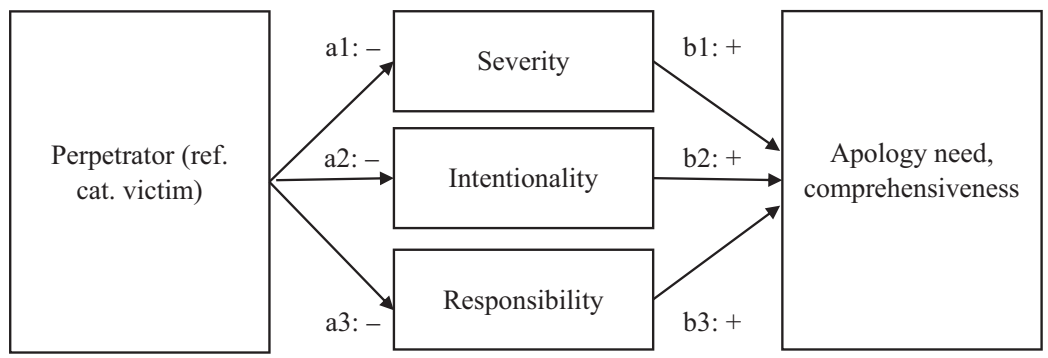

(b)

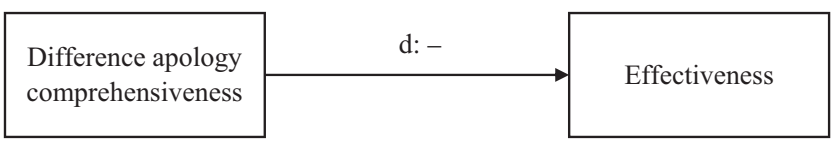

Figure 1: (a) Theoretical model: apology comprehensiveness as a function of differences between victim and perpetrator perceptions of severity, intentionality, and responsibility.

(b) Theoretical model: effect of difference in apology comprehensiveness on effectiveness.

We test this model in two scenario studies which focus on torts involving personal injury, reflecting the domain of tort law where apologies are especially advocated (e. g. Berryman, 2017; Cohen, 1999; Kleefeld, 2017; Shuman, 2000; Vines, 2015), and that which was used in previous research to demonstrate positive remedial effects of (relatively comprehensive) apologies (Robbennolt, 2006; Rachlinski 
et al., 2013). Study 1 examines victims' and perpetrators' desired comprehensiveness in apology. Study 2 examines the comprehensiveness of victims' and perpetrators' self-generated (desired vs. provided) apologies. Moreover, Study 2 presents victims with apologies from perpetrators, to examine how differences between their desired comprehensiveness and that provided by the perpetrator may impact remedial effectiveness. We test the following hypotheses:

- Hypothesis 1: perpetrators perceive lower severity, intentionality and responsibility in response to torts than victims do;

- Hypothesis 2: perpetrators perceive lower need for apologies in response to torts than victims do;

- Hypothesis 3: perpetrators provide lower comprehensiveness in apology in response to torts than victims desire;

- Hypothesis 4: perpetrators' less unfavorable perceptions of torts relative to victims explains their lower apology need and comprehensiveness;

- Hypothesis 5: perpetrators' apologies will be less effective the more their comprehensiveness falls short of victims' desires.

\section{Study 1}

\subsection{Method}

\subsubsection{Participants and design}

To conduct our studies, we relied on participants from the online crowdsourcing platform Prolific Academic, which in recent empirical legal research was demonstrated to compare favorably to laboratory samples (Irvine et al., 2018) as well as other online platforms such as Amazon Mechanical Turk (Peer et al., 2017) in terms of attentiveness, replication, and diversity. We recruited 123 participants (61 men, 62 women, $M_{\text {age }}=31.74, S D_{\text {age }}=10.38$ ) who were rewarded GPB 1.00 for their participation $\left(M_{\text {time }}=9\right.$ minutes $44, S D_{\text {time }}=5$ minutes 35$)$. Participants were randomly assigned to either the victim or the perpetrator condition.

\subsubsection{Materials}

Scenarios and role manipulation. Consistent with recent recommendations on replication (Irvine et al., 2018), we tested our hypotheses using multiple scenarios. As such, each participant was presented with three different scenarios during the study. The presentation order was randomized. 
The three scenarios described different personal injury incidents situated in everyday (working) life: (1) a situation where the perpetrator moved a chair as the victim was about to sit down, causing him/her to fall, hit his/her head, and suffer a concussion and minor injuries; (2) a situation where the perpetrator closed the door of an overcrowded train carriage and thereby traps the victim, hurting his/her arm and shoulder; and (3) a situation where the perpetrator pushes past the victim on the stairs, causing the victim to fall and bruise his/her back and legs. We constructed the scenarios so that they were ambiguous in terms of the intentionality or blameworthiness of the transgression, in order to leave room for participants' own interpretations. ${ }^{2}$

Participants' role in the scenarios was manipulated. In the victim condition, the scenarios described the incidents from the victim's perspective (see Appendix A). In the perpetrator condition, the incidents were described from the perpetrator's perspective (see Appendix B). Otherwise, the scenarios were identical.

The dependent measures were solicited following each of the scenarios. All items were measured on 7-point scales ( $1=$ not at all, 7 = very much).

Perceptions of severity, intentionality, and responsibility. Participants' transgression perceptions were assessed with five items: (1) "How severe do you consider this incident to be?" (2) "How severe do you consider the harm that resulted from this incident to be?" (3) "To what extent was it your intention to harm the other/the other's intention to harm you?" (4) "How intentional do you consider this incident to be?" and (5) "How responsible do you consider yourself/the other to be for this incident?". The items measuring severity $(r=0.80$, $p<0.001)$ and those measuring intentionality $(r=0.82, p<0.001)$ were combined into scale measures by computing the average of the two responses.

Need for apology. Perceptions of the need for apologies was measured with two items: (1) "How necessary is an apology in this situation?", and (2) "To what extent would you want the other to apologize to you/would you want to apologize to the other?". Responses were combined into a scale measure of perceived need for apology ( $r=0.83, p<0.001)$.

Apology comprehensiveness. Apology comprehensiveness was measured with six items, which assessed participants' desire for/willingness to provide six key apology components (Fehr and Gelfand, 2010; Lazare, 2004; Schumann, 2014):

2 We do so because (1) ambiguity characterizes the majority of real-world interpersonal transgressions (Adams and Inesi, 2016), and (2) ambiguous transgressions provide greater scope for contrasting interpretations. Note, however, that contrasting interpretations between victims and perpetrators have also been observed in case of clear transgressions (Leunissen et al., 2013). Thus, similar results might be expected there (though perhaps more muted than in the present, ambiguous context). 
"To what extent would you want the other to/would you ..." (1) "express remorse (say sorry)?”, (2) “accept responsibility for the incident”, (3) "acknowledge the fact that he/she harmed you/that you harmed the other", (4) "express sympathy for your/the other's hurts", (5) “explicitly promise to never do so again”, and (6) "offer to make amends or compensate you/the other". Their responses were reduced into a single (weighted) component score $(\alpha=0.81)$ by means of principal component analysis, which constitutes our measure of apology comprehensiveness.

\subsubsection{Procedure}

In each of the three scenarios, participants were instructed to carefully read the vignette, to imagine themselves in the situation, and to then complete the dependent questions. After completing the last scenario, the study ended.

\subsection{Results}

As our focus is on global differences between victims' and perpetrators' perspectives on transgressions and apology, we collapsed participants' responses across scenarios, for reasons of parsimony. ${ }^{3}$ We controlled for presentation order in all analyses.

\subsubsection{Perceptions of severity, intentionality, and responsibility}

Participants' transgression perceptions were analyzed in a two-level (victim vs perpetrator), multivariate analysis of variance (MANOVA). MANOVA tests the effect of the independent variable (role) on multiple dependent variables (perceptions of severity, intentionality, and responsibility), while taking into account their interrelationship. As such, MANOVA illuminates whether conditions can be distinguished by a combination of scores on several dependent measures, with less danger of producing a false positive. Using Pillai's trace, there was a significant multivariate effect of role on transgression perceptions, indicating victims and perpetrators to differ significantly in their transgression perceptions (Table 1). To

3 Although considerable differences were observed between scenarios (i. e. Scenario 1 was generally perceived as more severe, intentional, and responsible to the perpetrator than Scenario 3, with Scenario 2 differing from both), a 2 (Role: victim vs perpetrator) x 3 (Scenario) repeated measures analysis of variance indicated the reported differences in transgression perceptions, need for apology and apology content between victims and perpetrators to be robust across scenarios. For this reason, we present the (more parsimonious) analyses on the aggregated data here. 
Table 1: Means and standard deviations (in parentheses) for transgression perceptions as a function of role (victim vs. perpetrator), study 1.

\begin{tabular}{|c|c|c|c|c|c|c|c|}
\hline & \multicolumn{2}{|c|}{ Role } & \multicolumn{3}{|c|}{ MANOVA } & \multicolumn{2}{|c|}{ ANOVA } \\
\hline & Victim & Perpetrator & $\boldsymbol{v}$ & $F(3,118)$ & $p$ & $F(1,120)$ & $p$ \\
\hline $\begin{array}{l}\text { Transgression } \\
\text { perceptions }\end{array}$ & & & 0.25 & 13.47 & 0.000 & & \\
\hline Severity & $5.50(0.78)$ & $5.19(0.92)$ & & & & 4.04 & 0.047 \\
\hline Intentionality & $4.16(1.16)$ & $2.88(1.07)$ & & & & 40.81 & 0.000 \\
\hline Responsibility & $5.57(0.98)$ & $5.07(1.08)$ & & & & 7.14 & 0.009 \\
\hline
\end{tabular}

explore the nature of these differences, follow-up analyses were conducted using univariate analyses of variance (ANOVA). Their results indicated that perpetrators perceived transgressions as less severe and intentional than victims did, and attributed lower responsibility for them to themselves. This supports Hypothesis 1. Need for apology. ANOVA on need for apology indicated a marginal main effect of role, $F(1,120)=3.60, p=0.060$, indicating perpetrators to perceive a somewhat lower need for apologies $(M=5.86, S D=0.94)$ than victims $(M=6.16$, $S D=0.78)$. This result is consistent with Hypothesis 2.

\subsubsection{Apology comprehensiveness}

Analysis of variance on the apology comprehensiveness component score revealed a significant main effect of role (see Table 2). Perpetrators were less inclined to apologize comprehensively than victims desired. This result supports Hypothesis 3.

Table 2: Means and standard deviations (in parentheses) for apology components and comprehensiveness factor score as a function of role (victim vs. perpetrator), study 1.

\begin{tabular}{|c|c|c|c|c|c|c|c|}
\hline & \multicolumn{2}{|c|}{ Role } & \multicolumn{3}{|c|}{ MANOVA } & \multicolumn{2}{|c|}{ ANOVA } \\
\hline & Victim & Perpetrator & $\boldsymbol{v}$ & $F(6,115)$ & $p$ & $F(1,120)$ & $p$ \\
\hline Apology elements & & & 0.18 & 4.18 & 0.000 & & \\
\hline Remorse & $6.24(0.91)$ & $6.05(0.96)$ & & & & 1.30 & 0.267 \\
\hline Accept responsibility & $6.02(0.90)$ & $5.32(1.10)$ & & & & 14.78 & 0.000 \\
\hline Acknowledge harm & $6.29(0.83)$ & $5.75(1.01)$ & & & & 10.53 & 0.002 \\
\hline Express sympathy & $5.76(1.33)$ & $5.67(1.22)$ & & & & 0.14 & 0.713 \\
\hline Promise forbearance & $5.03(1.45)$ & $4.85(1.45)$ & & & & 0.46 & 0.498 \\
\hline Offer compensation & $4.19(1.68)$ & $4.05(1.61)$ & & & & 0.23 & 0.630 \\
\hline $\begin{array}{l}\text { Apology compre- } \\
\text { hensiveness } \\
\text { (weighted factor score) }\end{array}$ & $0.20(0.86)$ & $-0.21(1.04)$ & & & & 5.31 & 0.023 \\
\hline
\end{tabular}




\subsubsection{Structural model}

To test our theoretical model, we estimated a structural equation model using the lavaan package (Rosseel, 2012) in R (R Core Team, 2013). In this model, need for apology (Figure 2) and apology comprehensiveness (Figure 3) were regressed upon perceptions of severity, intentionality, and responsibility, which in turn were regressed on the manipulation of role $(0=$ victim, $1=$ perpetrator $) .^{4}$

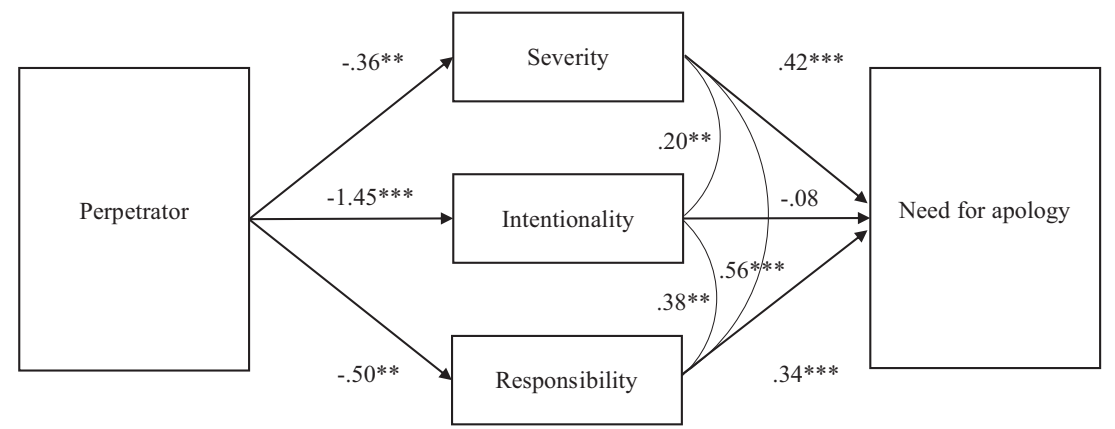

Figure 2: Structural model, need for apology, study 1.

Note: ${ }^{\star \star *}=p<.001,{ }^{\star *}=p<.05,{ }^{*}=p<.10$.

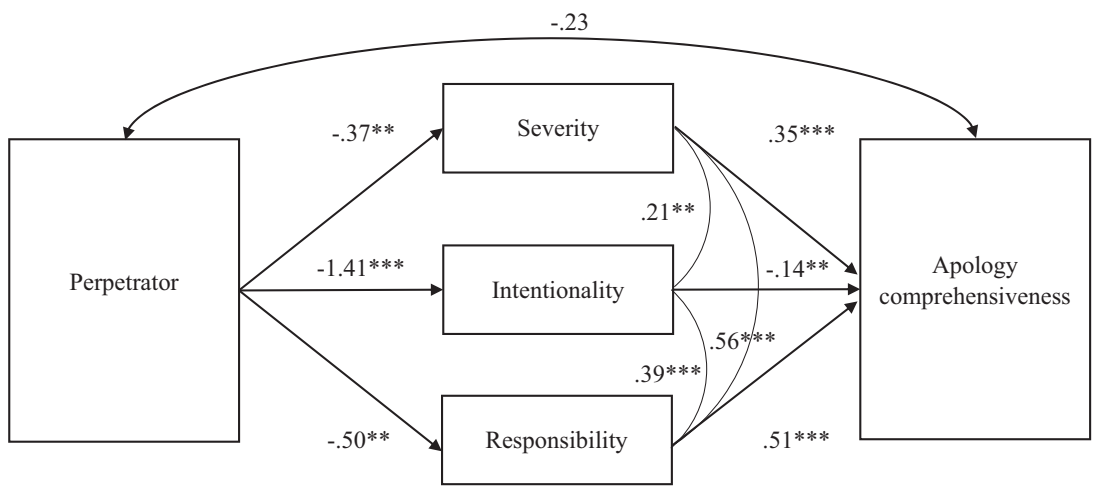

Figure 3: Structural model, apology content, study 1.

Note: ${ }^{\star \star *}=p<.001,{ }^{* *}=p<.05,{ }^{*}=p<.10$.

4 With regard to apology content, our models focus on apology comprehensiveness, rather than separating the individual apology components. The reason for this is (1) our theoretical framework, which focuses on apology comprehensiveness, and (2) the greater complexity of models separating the individual apology components. For interested readers, models that separate the individual apology components are available from the authors on request. 
Need for apology. Figure 2 displays the structural model for need for apology. As can be seen, perceptions of greater severity and responsibility predicted greater need for apology. Perceptions of severity and responsibility were lower among perpetrators than among victims. Moreover, their multiplicative effects differed significantly from zero (severity: $\mathrm{a}^{\star} \mathrm{b}=-0.15, p=0.045$; responsibility: $\mathrm{a}^{\star} \mathrm{b}=-0.18, p=0.012$ ). Thus, perpetrators' more favorable transgression perceptions mediated their lower perceived need for apology relative to victims. This finding supports Hypothesis 4. Their lower perceptions of intentionality were not significantly associated with this outcome.

Apology comprehensiveness. Figure 3 displays the structural model for apology comprehensiveness. Perceptions of greater severity and responsibility predicted greater apology comprehensiveness. Perpetrators perceived lower severity and responsibility than victims. Furthermore, their multiplicative effects differed significantly from zero (severity: $\mathrm{a}^{\star} \mathrm{b}=-0.13, p=0.047$; responsibility: $\mathrm{a}^{\star} \mathrm{b}=-0.24, p=0.010$ ). Thus, perpetrators' more favorable transgression perceptions also mediated their inclination toward lower apology comprehensiveness, relative to that desired by victims. This result also supports Hypothesis 4.

In contrast, perceptions of greater intentionality predicted lower apology comprehensiveness. Perpetrators perceived lower intentionality than victims did. The multiplicative effect of these associations fell short of significance $\left(a^{\star} b=0.15\right.$, $p=0.059$ ). The general pattern, however, seems to suggest that perpetrators' more favorable perceptions of the intentionality of their transgressions increased the comprehensiveness of their apologies. This result differs from Hypothesis 4.

\subsection{Discussion}

The results of Study 1 provided considerable support for our hypotheses. In line with Hypothesis 1, perpetrators showed less unfavorable perceptions of transgressions than victims did. Consistent with Hypotheses 2 and 3, perpetrators also perceived a lower need for apologies, and provided lower comprehensiveness in apology than victims desired. Lastly, mediation analyses revealed these differences in need for, and comprehensiveness of apology to be explained by their contrasting transgression perceptions, as predicted by Hypothesis 4. Thus, these findings provide strong support for our theoretical model.

One noteworthy deviation from our expectations concerns the role of intentionality. As expected, perpetrators perceived transgressions as less intentional than victims did, and this discrepancy influenced the difference in comprehensiveness between their (provided and desired) apologies. The direction of this association, however, differed from our assumptions, by indicating a negative relationship: 
perceptions of greater intentionality predicted lower comprehensiveness in apology. We will explore this process in more detail in the General Discussion.

\section{Study 2}

Study 2 aimed to extend the results of Study 1 in two major ways. Firstly, we aimed to examine whether the observed differences between victims and perpetrators in the comprehensiveness of apology were also reflected in their actual, self-generated apologies. As such, Study 2 solicited actual, written apologies that victims desired, and perpetrators provided in response to each of the scenarios. Secondly, we aimed to examine how the observed difference in comprehensiveness might affect the effectiveness of apology. To this end, victims were presented with the apologies provided by the perpetrators, and their effectiveness was measured.

\subsection{Method}

\subsubsection{Participants and design}

We recruited 202 respondents (111 men, 91 women, $M_{\text {age }}=30.51, S D_{\text {age }}=9.00$ ) via Prolific Academic. We collected our data in two stages. First, a sample was collected for the perpetrator condition $(N=100)$. Next, a sample was collected for the victim condition $(N=102)$. This procedure enabled each victim to be paired with a perpetrator, whose apology was presented to them during the study. Participants were rewarded GPB 1.00 for their participation $\left(\mathrm{M}_{\text {time }}=9\right.$ minutes $09, \mathrm{SD}_{\text {time }}=5$ minutes 21). No participants from Study 1 took part in the study, and participants included in the perpetrator sample were excluded from the victim sample.

\subsubsection{Procedure}

The study consisted of two parts. Part I included all 202 participants. Similar to Study 1 , this section focused on the content that victims desired, and perpetrators provided in apology in response to the three scenarios (identical to Study 1). Contrary to the closed-ended measures employed in Study 1, however, Study 2 employed an open-ended question format, in which participants themselves generated the content of their apologies. These responses were coded by the researchers and compared between conditions. 
Part II included only the participants from the victim condition. This section focused on the question how differences between the desired and provided content of apologies impact their remedial effectiveness. To this end, victims were presented with the apologies that had been provided by a counterpart from the perpetrator condition, after which their ratings of effectiveness were measured. ${ }^{5}$

\subsubsection{Materials}

Perceptions of severity, intentionality, and responsibility. We used the same items to measure transgression severity $(r=0.81, p<0.001)$, intentionality $(r=0.89, p<0.001)$, and responsibility.

Apology comprehensiveness. The content of the apologies provided by perpetrators and desired by victims was coded using a coding scheme based on Schumann (2014), centered on the six elements that were distinguished in Study 1. As such, participants' apologies were scored according to their provision of remorse (e.g. "I'm sorry"; "I apologize”), acceptance of responsibility (e.g. "it was my fault"; "I should not have done that"), acknowledgement of harm (e. g. "I feel terrible that you were hurt because of me"), sympathy (e. g. "are you OK?”), promises of forbearance (“it won't happen again”), and offers of repair ("please allow me to make it up to you"). Relative to the more elaborate typology of Schumann (2014), our coding scheme omitted categories that were rarely encountered (e. g. request for forgiveness) and combined categories that proved difficult to separate in practice (e.g. acceptance of responsibility and admission of wrongdoing, e. g. "it was wrong of me to do what I did"). In response to raters' experiences, the coding scheme was expanded with two defensive categories, namely claimed inadvertence (e. g. "that was completely unintentional") and exoneration ("I was in a hurry"; "you were in my way"; "I did it for the right reasons").

The apologies were coded by two independent raters. An initial set of 10 cases was coded by both raters as a preliminary test of the coding scheme. While both sets of codings generally displayed high consistency, some ambiguity resulted from the notion that transgressions in the present context involved physical harm - such that accepting responsibility for the offense could simultaneously imply acknowledgment of harm (e.g. "I am truly sorry for hurting you"). In response to this, the coding scheme was revised to its final version, in

5 Due to an error in the program, two surplus participants took part in the victim condition, and received identical apologies to another participant. Because elimination of these cases did not alter the results, they were retained in the final analysis. One participant in the victim condition was eliminated for failure to follow the instructions. 
which the category of acceptance of responsibility was focused more explicitly on the act itself (e.g. pushing the victim down the stairs) and the category of acknowledging harm more on its consequences for the victim (e.g. the victim being hurt). Following these revisions, an initial set of responses (34 participants, 102 apologies) coded by both raters indicated high levels of interrater reliability over all categories (Krippendorff's alpha $=0.91$ ). The remaining cases were equally divided and coded individually. Where appropriate, ambiguous cases were resolved by discussion before resolving upon a final coding.

To construct a measure of apology comprehensiveness, a single weighted component score was constructed from the six apology elements, as in Study 1. The two defensive elements (not assessed in Study 1) were analyzed separately.

Effectiveness. Effectiveness was measured with two items: ("If the other would respond to the incident with this message ... ") (1) "to what extent would his/her response satisfy your needs?", and (2) "how likely would you be to forgive him/her?". They were combined into a scale measure of effectiveness $(r=0.85, p<0.001)$ by computing the average of the two responses.

\subsection{Results}

Our analysis consists of two steps. Firstly, we focus on the results of Stage I, which examined how victims and perpetrators may differ in transgression perceptions and comprehensiveness in apology. Secondly, we focus on the results of Stage II, which examined how the difference between victims' desired, and perpetrators' provided level of comprehensiveness may impact apology effectiveness. As in Study 1, participants' responses were collapsed across the three scenarios. ${ }^{6}$ All analyses controlled for presentation order.

\subsubsection{Perceptions of severity, intentionality, and responsibility}

A two-level (victim vs perpetrator) MANOVA on participants' transgression perceptions indicated a significant multivariate effect of role on transgression perceptions. Subsequent ANOVAs (Table 3) indicated that perpetrators perceived

6 As in Study 1, a 2 (Role: victim vs perpetrator) x 3 (Scenario) repeated measures analysis of variance indicated significant differences between scenarios, such that Scenario 1 was generally perceived as more severe, intentional, and responsible to the perpetrator than Scenarios 2 and 3, and displayed stronger differences between the perceptions of victims and perpetrators. However, the observed main effects for perceived intentionality and apology content were robust across scenarios. For these reasons, we again report the analysis of the (more parsimonious) aggregated data here. 
Table 3: Means and standard deviations (in parentheses) for transgression perceptions as a function of role (victim vs. perpetrator), study 2 .

\begin{tabular}{|c|c|c|c|c|c|c|c|}
\hline & \multicolumn{2}{|c|}{ Role } & \multicolumn{3}{|c|}{ MANOVA } & \multicolumn{2}{|c|}{ ANOVA } \\
\hline & Victim & Perpetrator & $\boldsymbol{V}$ & $F(3,195)$ & $p$ & $F(1,198)$ & $p$ \\
\hline $\begin{array}{l}\text { Transgression } \\
\text { perceptions }\end{array}$ & & & 0.32 & 30.37 & 0.000 & & \\
\hline Severity & $5.30(0.89)$ & $5.19(0.85)$ & & & & 0.65 & 0.422 \\
\hline Intentionality & $4.16(1.16)$ & $2.67(1.08)$ & & & & 83.11 & 0.000 \\
\hline Responsibility & $5.48(1.16)$ & $5.33(1.08)$ & & & & 0.98 & 0.323 \\
\hline
\end{tabular}

transgressions to be significantly less intentional than victims did. There were no significant differences in perceptions of severity and responsibility, however. These findings thus provide partial support for Hypothesis 1.

\subsubsection{Apology comprehensiveness}

Analysis of variance on the apology comprehensiveness component score revealed that perpetrators' apologies were significantly less comprehensive in content than those that victims desired (Table 4). This finding replicates the results of Study 1, and

Table 4: Means and standard deviations (in parentheses) for inclusion of apology components and comprehensiveness factor score as a function of role (victim vs. perpetrator), study 2 .

\begin{tabular}{|c|c|c|c|c|c|c|c|}
\hline & \multicolumn{2}{|c|}{ Role } & \multicolumn{3}{|c|}{ MANOVA } & \multicolumn{2}{|c|}{ ANOVA } \\
\hline & Victim & Perpetrator & $\boldsymbol{v}$ & $F(8,191)$ & $p$ & $F(1,198)$ & $p$ \\
\hline Apology elements & & & 0.10 & 2.80 & 0.006 & & \\
\hline Remorse & $0.97(0.11)$ & $0.94(0.17)$ & & & & 2.45 & 0.119 \\
\hline Accept responsibility & $0.55(0.35)$ & $0.40(0.37)$ & & & & 8.89 & 0.003 \\
\hline Acknowledge harm & $0.41(0.36)$ & $0.38(0.36)$ & & & & 0.24 & 0.623 \\
\hline Express sympathy & $0.11(0.20)$ & $0.20(0.28)$ & & & & 4.73 & 0.031 \\
\hline Promise forbearance & $0.07(0.18)$ & $0.03(0.13)$ & & & & 3.05 & 0.082 \\
\hline Offer compensation & $0.21(0.30)$ & $0.20(0.30)$ & & & & 0.15 & 0.702 \\
\hline $\begin{array}{l}\text { Apology compre- } \\
\text { hensiveness } \\
\text { (weighted factor score) }\end{array}$ & $0.21(0.85)$ & $-0.21(1.10)$ & & & & 9.42 & 0.002 \\
\hline Defensive elements & & & & & & & \\
\hline Claim inadvertence & $0.28(0.31)$ & $0.37(0.29)$ & & & & 0.86 & 0.353 \\
\hline Exonerate & $0.43(0.36)$ & $0.53(0.35)$ & & & & 5.49 & 0.020 \\
\hline
\end{tabular}


provides additional support for Hypothesis 3. Additionally, perpetrators displayed significantly greater exoneration in their apologies than victims did. For claims of inadvertence, no significant differences were observed.

\subsubsection{Structural model}

To test whether the mechanisms observed in Study 1 were replicated in Study 2, we again estimated a structural equation model (Figure 4). Consistent with Study 1, perceptions of greater severity and responsibility displayed positive associations to apology comprehensiveness, while perceptions of greater intentionality displayed a negative association with this outcome. The role of perpetrator showed negative associations to perceived severity, intentionality and responsibility. Globally, the model therefore mirrors the associations observed in Study 1.

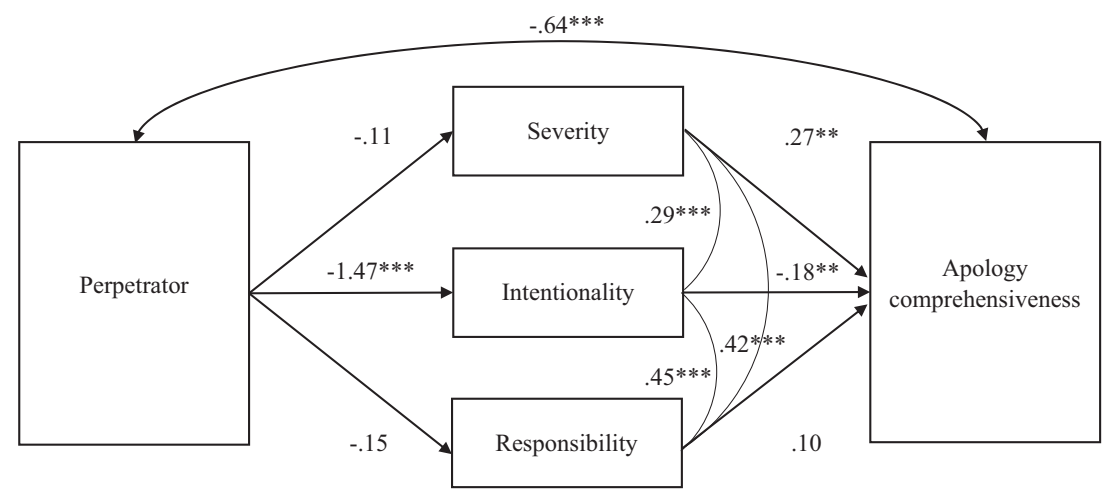

Figure 4: Structural model, apology content, study 2.

Note: ${ }^{\star \star \star}=p<.001,{ }^{\star \star}=p<.05,{ }^{\star}=p<.10$.

Contrary to Study 1, the role of perpetrator only predicted lower perceptions of intentionality, while greater perceptions of intentionality predicted lower apology comprehensiveness. Moreover, the multiplicative effect of their associations differed significantly from zero $\left(a^{\star} b=0.25, p=0.011\right)$. As such, the model suggests that perpetrators' more favorable perceptions of intentionality mediated the comprehensiveness of their apologies, and attenuated its difference relative to what victims desired. The opposite effect through perceptions of severity and responsibility was not replicated, as their associations with role did 
not reach significance in the present model, nor did that between responsibility and apology comprehensiveness. In sum, these findings thereby partially replicate the results of Study 1.

\subsubsection{Effectiveness}

Lastly, we examined how comprehensiveness might impact the remedial effectiveness of apologies. We firstly examine how the absolute level of comprehensiveness of perpetrators' apologies (i. e. comprehensiveness component score) impacts victims' ratings of effectiveness. Next, we examine how the effectiveness of apology may be influenced by the difference between the comprehensiveness that victims desire, and perpetrators provide (i. e. difference between victim and perpetrator component scores). For these analyses, we relied on linear regression analyses. Scores for the defensive elements were included as additional predictors.

The effect of the comprehensiveness of perpetrators' apology was significant and positive, $b=0.52, t(96)=3.62, p<0.001$, such that victims indicated greater effectiveness in response to more comprehensive apologies. Claims of inadvertence $(b=0.06, t[96]=0.39, p=0.70)$ and exoneration $(b=-0.02, t[96]=-0.11$, $p=0.91)$ did not affect effectiveness.

Additionally, difference between victims' desired, and perpetrators' provided apologies was negatively associated with effectiveness, $b=-0.42, t(96)=-2.87$, $p<0.01$. The more that the comprehensiveness of perpetrators' apologies fell short from that which victims desired, the lower were victims' ratings of its effectiveness. Both results support Hypothesis 5. Apology effectiveness was not influenced by differences in claims of inadvertence $(b=-0.05, t[96]=-0.37, p=0.71)$ or exoneration $(b=0.13, t[96]=0.88, p=0.38)$.

\subsection{Discussion}

Study 2 provided additional support for our hypotheses by partially replicating the results of Study 1, and by extending them to the remedial effectiveness of apology. Study 2 again demonstrated that perpetrators provide lower comprehensiveness in apology in response to torts than victims desire. Thereby, Study 2 provides additional support for Hypothesis 3. Differences in comprehensiveness again were associated with perpetrators' tendency to perceive their transgressions as less intentional than victims. Study 2 moreover revealed that less comprehensive apologies, and apologies that differed more from the comprehensiveness that victims desired, evoked lower ratings of effectiveness, supporting Hypothesis 5. 
We did not replicate the differences between victims' and perpetrators' perceptions of transgression severity and responsibility, though; therefore, the findings of Study 2 do not fully support Hypothesis 1 or 4. The direction of their associations with both role and apology comprehensiveness was consistent with those observed in Study 1, however (see Figures 3 and 4), providing some support for the patterns observed there.

\section{General discussion}

In legal theory and practice, initiatives to facilitate apologies are increasingly advocated and adopted, inspired by the belief that apologies can enhance victims' restoration after torts (Cohen, 1999; Latif, 2001; Robbennolt, 2003, 2006; Vines, 2015). The present research aimed to understand whether the apologies that perpetrators offer in response to torts in fact may live up to their remedial potential. More specifically, the present research examined to what extent the comprehensiveness that perpetrators offer in apology in response to torts corresponds with that which victims desire - and how discrepancies in comprehensiveness may impact the remedial effectiveness of apology.

\subsection{Evidence for theoretical model and hypotheses}

Generally, our findings provided considerable support for our predictions, and for our theoretical model. In context of (hypothetical) personal injury incidents, perpetrators regarded apologies as less necessary, and apologized less comprehensively than victims desired, supporting Hypotheses 2 and 3. Moreover, differences between the desired and provided comprehensiveness of apology were shown to reduce remedial effectiveness, in line with Hypothesis 5. Our findings therefore support the idea that perpetrators' apologies in response to torts may fail to live up to victims' expectations, undermining their remedial effectiveness.

The results also confirmed our prediction that miscalibration between what victims desire, and perpetrators offer in apology may be rooted in contrasting perceptions of torts. Both studies indicated that perceptions of severity, responsibility and intentionality predicted the comprehensiveness of apology. Moreover, both studies demonstrated that such perceptions may differ between victims and perpetrators (severity and responsibility in Study 1; intentionality in Studies 1 and 2). And finally, both studies revealed that their differing perceptions of torts explained the differing comprehensiveness of their desired and 
actual apologies. This way, our findings also provided considerable support for Hypotheses 1 and 4.

Although our findings support our prediction that disputants' contrasting perceptions of torts may contribute to mismatched apologies, the way in which they do so deserves some further analysis. Perceptions of greater severity (Studies 1 and 2) and responsibility (Study 1) were associated with more comprehensive apologies. By demonstrating victims to perceive torts as more severe, and more responsible to the perpetrator than perpetrators did, Study 1 supported our prediction that perpetrators' more favorable perceptions of torts lead them to apologize less comprehensively than victims desire. For perceptions of intentionality, however, our findings suggested a reversed pattern, such that perceptions of greater intentionality were associated with lower comprehensiveness. How can this finding be understood? One possibility may be that this association differs between victims and perpetrators. Indeed, prior research shows that perpetrators (but not victims) may regard apologies as less necessary in case of intentional transgressions (Leunissen et al., 2013). In the present study, however, no moderation of the association between intentionality and comprehensiveness was observed when conducting a moderated mediation analysis ( $b=0.00, \mathrm{SE}=0.14,95 \%$ C.I. [-0.29; 0.29], PROCESS model 74 [Hayes, 2013], 10,000 bootstrap samples). Alternatively, this association could reflect the notion that apologies may lose their credibility after intentional transgressions (Struthers et al., 2008). According to this reasoning, both victims and perpetrators may see less value in apology following more intentional transgressions, and consequently may forego greater comprehensiveness.

Further research is needed to understand how these mechanisms may operate, and in which processes they may be rooted (e. g. informational differences, Malle, 2006; self-serving biases, Kearns and Fincham, 2005). Such research should also extend the present analysis to include perceptions of concepts that are central to litigation, such as (perceived) negligence. But while the present findings do not yet resolve the processes that underlie these effects, their consequences are clear: that perpetrators provide less comprehensiveness in apology than victims desire, undermining their remedial effectiveness in the resolution of torts.

\subsection{Strengths and limitations}

To examine mismatches in apology content, our research relied on studies involving both closed-ended (Study 1) and open-ended (Study 2) measures. By relying on experimental scenarios, consistent with the most influential legal research on 
apology (Robbennolt, 2003, 2006), our studies enabled us to present participants with identical cases; for further robustness, each study contained three separate scenarios in which our theoretical model was tested. Across studies and scenarios, we obtained considerable support for our hypotheses. Moreover, while the effects were generally somewhat less pronounced in Study 2 - an observation that may be explained by its use of open-ended measures, and by victims' exposure to perpetrators' apologies - the causal relationships between the focal concepts (see Figures 2, 3, and 4) were identical in either study. Therefore, an important strength of the present research is our replication of effects across different scenarios, methods, and studies, and the methodological rigor provided by their experimental approach. The flipside of this approach is that our research did not examine actual torts or litigants in court settings. It is possible that direct experience with trials might influence people's needs for, and restoration through apology. However, relative to the content of our scenarios, actual torts are likely to be characterized by more prominent strategic concerns (e. g. fears over liability, see Latif, 2001; Van Dijck, 2018b; Vines, 2008), which are likely to further limit the comprehensiveness of perpetrators' apologies. In other words, our findings may underestimate the lack of remedial effectiveness of apologies in court settings. Nevertheless, replication of the present findings among actual litigants, potentially within a system where initiatives to facilitate apology are in place (e. g. Latif, 2001; Vines, 2008; Wagatsuma and Rosett, 1986), would constitute a valuable avenue for future research.

\subsection{Implications}

By providing insight on the content and comprehensiveness of the apologies that victims desire, and perpetrators provide in response to torts, the present research contributes important insight for both theorizing and practical initiatives concerned with the role of apology in tort law. In light of evidence on the remedial potential of apology, attention in this domain is primarily focused on the provision of apologies, and on the merit of legal measures to facilitate this (e. g. Latif, 2001; Vines, 2008; White, 2005). The present research contributes to this discussion in two important ways. Firstly, it highlights the importance of considering the content of apology in the discussion on these questions. As the present research shows, the content that perpetrators provide in response to torts may not correspond with what victims desire, with detrimental effect on its remedial value. Discussions on this topic in legal theorizing and practice therefore should evaluate the merit of apology in terms of its content, not just its provision. Secondly, the present research enriches this discussion by revealing 
that litigants' underutilization of apology is rooted in their contrasting interpretations of torts, which may be embedded in both strategic and nonstrategic reasons such as informational distortions. This latter conclusion is especially relevant when considering that nonstrategic reasons may not be overcome by provisions to facilitate apology, like apology protection laws.

\subsection{Overcoming differences in apology comprehensiveness}

When considering the observed discrepancy between what victims desire, and perpetrators provide in apology, and its detrimental consequences for the effectiveness of apology, an important question is how such discrepancies can be reduced in context of tort litigation. The question of how to do so is contingent on the processes that underlie this discrepancy. To the extent that such discrepancies are the result of strategic reasons, such as concerns over liability, it may indeed be the case that provisions to protect apology will be needed to enable more comprehensive apologies. Legal protection may enable the inclusion of more incriminating elements, and thereby may lead perpetrators to offer more comprehensive apologies. Whether doing so will fully resolve the observed discrepancy in comprehensiveness is an unresolved question, however. Legal protection of apology may also undermine the cost and perceived sincerity of apology (Corbett, 2013; White, 2005), and thereby increase not only what perpetrators provide, but also what victims desire in apology. Moreover, perpetrators may continue to avoid particular elements due to their negative implications for the self (e.g. accepting responsibility for one's transgressions threatens one's favorable self-image, see Schumann, 2014; Leunissen et al., 2014).

To the extent that discrepancies in comprehensiveness are rooted in litigants' contrasting perception of torts, however, a solution would need to create insight into each other's perspective - and if possible, to reconcile them. One important means for this purpose may be alternative dispute resolution (ADR, see Sherman et al., 2005; also see Carroll et al., 2017; Choi and Severson, 2009). ADR encompasses a range of extralegal provisions for dispute resolution, including mediation and restorative justice, which empower disputants themselves for the resolution of their disputes. One important aspect of such techniques is providing disputants with insight into each other's perspectives and needs for the resolution of their disputes. In this respect, ADR could provide disputants with a balanced, multifaceted perspective on torts, and with greater understanding of their counterpart's desired remedies. Either of these process could help to reduce mismatches in apology. As such, ADR may provide a critical means of enabling more 
comprehensive and satisfying apologies, which are better equipped to capitalize on their remedial potential in the resolution of torts.

Acknowledgements: This research was supported by a grant from the Erasmus School of Law Innovation Programme, awarded to the first author. The authors thank Pieter van Dalsen for his assistance with the coding of the open-ended responses.

\section{Appendix A: Scenarios (Victim Perspective)}

\section{Scenario 1}

A meeting at work results in a heated debate between you and one of your colleagues. When the meeting resumes after a break, this colleague grabs your chair just as you are about to sit down. As a result of this, you fall, and hit your head. You suffer a mild concussion, bruises, and pain to your lower back.

\section{Scenario 2}

Due to a technical defect, the train service for your daily commute is heavily disrupted, and the trains consequently are overcrowded. Even so, you and other commuters on the platform are trying to force your way into a carriage. One of the commuters inside the carriage presses the button to close the doors to prevent this. You get stuck between the closing doors, and hurt your arm and shoulder.

\section{Scenario 3}

At work, you are talking with some colleagues in the stairway. Another employee is on his/her way down the stairs, in a hurry for an important appointment. When you and your colleagues do not immediately get out of your the way, he/she forces his/her way past you. This causes you to fall down the stairs. You suffer extensive bruising to your back and legs.

\section{Appendix B: Scenarios (Perpetrator Perspective)}

\section{Scenario 1}

A meeting at work results in a heated debate between you and one of your colleagues. When the meeting resumes after a break, you grab this colleague's chair, just as he/she is about to sit down. As a result of this, the colleague falls, 
and hits his/her head. The colleague suffers a mild concussion, bruises, and pain to his/her lower back.

\section{Scenario 2}

Due to a technical defect, the train service for your daily commute is heavily disrupted, and the trains consequently are overcrowded. Even so, more commuters on the platform are trying to force their way into your carriage. You press the button to close the door to prevent this. One of the commuters gets stuck between the closing doors, hurting his arm and shoulder.

\section{Scenario 3}

At work, you are in a hurry for an important appointment. On your way down the stairs, some other employees are blocking the way while talking. When they do not immediately get out of your the way, you force your way past them. This causes one of the employees to fall down the stairs. He/she suffers extensive bruising to his/her back and legs.

\section{References}

Abel, R.L. 2006. "General Damages are Incoherent, Incalculable, Incommensurable, and Inegalitarian (But Otherwise a Great Idea)," 55 DePaul Law Review 253-329.

Adams, G.S., and M.E. Inesi. 2016. "Impediments to Forgiveness: Victim and Transgressor Attributions of Intent and Guilt," 111 Journal of Personality and Social Psychology 866-881.

Allan, A., and R. Carroll. 2017. "Apologies in a Legal Setting: Insights from Research into Injured Parties' Experiences of Apologies after an Adverse Event," 24 Psychiatry, Psychology and Law 10-32.

Baumeister, R. F., A. M. Stillwell, and S. R. Wotman. 1990. "Victim and Perpetrator Accounts of Interpersonal Conflict: Autobiographical Narratives about Anger," 59 Journal of Personality and Social Psychology 994-1005.

Berryman, J. 2017. “Mitigation, Apology and the Quantification of Non-Pecuniary Damages," 7 Oñati Socio-Legal Series 528-546.

Carroll, R. 2013. "Apologies as a Legal Remedy," 35 Sydney Law Review 317-347.

Carroll, R., A. Allan, and M. Halsmith. 2017. "Apologies, Mediation and the Law: Resolution of Civil Disputes," 7 Oñati Socio-Legal Series 569-600.

Carroll, R., and N. Witzleb. 2011. "It's Not Just about the Money - Enhancing the Vindicatory Effect of Private Law Remedies," 37 Monash University Law Review 216-240.

Choi, J.J., and M. Severson. 2009. "“What! What Kind of Apology Is This?": The Nature of Apology in Victim Offender Mediation," 31 Children and Youth Services Review 813-820.

Cohen, J.R. 1999. “Advising Clients to Apologize,” 72 Southern California Law Review 1009-1069. Corbett, V. 2013. "Why It's Better to Be Sorry than Safe: The Case for Apology Protection Legislation,” 36 Dublin University Law Review 128-153. 
Darley, J.M., and T.S. Pitman. 2003. "The Psychology of Compensatory and Retributive Justice," 7 Personality and Social Psychology Review 324-336.

Day, M.V., and M. Ross. 2011. "The Value of Remorse: How Drivers' Responses to Police Predict Fines for Speeding," 35 Law and Human Behavior 221-234.

De Cremer, D., M. M. Pillutla, and C. Reinders Folmer. 2011. "How Important Is an Apology to You? Forecasting Errors in Evaluating the Value of Apologies," 22 Psychological Science 45-48.

Dhami, M.K. 2012. "Offer and Acceptance of Apology in Victim-Offender Mediation," 20 Critical Criminology 45-60.

Dhami, M.K. 2017. “An Empirical Note on Perceptions of Partial Apologies,” 7 Oñati Socio-Legal Series 408-420.

Fehr, R., and M. Gelfand. 2010. "When Apologies Work: How Matching Apology Components to Victims' Self-Construals Facilitates Forgiveness," 113 Organizational Behavior and Human Decision Processes 37-50.

Felson, R.B., and J.T. Tedeschi. 1993. Aggression and Violence: Social Interactionist Perspectives. Washington, DC: American Psychological Association.

Fisher, M.L., and J.J. Exline. 2010. "Moving toward Self-Forgiveness: Removing Barriers related to Shame, Guilt, and Regret," 4 Social and Personality Psychology Compass 548-558.

Hayes, A. F. 2013. An Introduction to Mediation, Moderation, and Conditional Process Analysis: A Regression-Based Approach. New York, NY: Guilford Press.

Hulst, L., and A.J. Akkermans. 2011. "Can Money Symbolize Acknowledgment? How Victims' relatives Perceive Monetary Awards for Their Emotional Harm," 4 Psychological Injury and Law 245-262.

Irvine, K., D.A. Hoffman, and T. Wilkinson-Ryan. 2018. "Law and Psychology Grows Up, Goesonline, and Replicates," 15 Journal of Empirical Legal Studies 320-355.

Kearns, J.N., and F.D. Fincham. 2005. "Victim and Perpetrator Accounts of Interpersonal Transgressions: Self-Serving or Relationship-Serving Biases?," 31 Personality and Social Psychology Bulletin 321-333.

Kirchhoff, J., U. Wagner, and M. Strack. 2012. "Apologies: Words of Magic? the Role of Verbal Components, Anger Reduction, and Offence Severity," 18 Peace and Conflict: Journal of Peace Psychology 109-130.

Kleefeld, J.C. 2017. "Promoting and Protecting Apologetic Discourse through Law: A Global Survey and Critique of Apology Legislation and Case Law," 7(3) Oñati Socio-Legal Series [Online] 455-496.

Latif, E. 2001. "Apologetic Justice: Evaluating Apologies Tailored Towards Legal Solutions," 81 Boston University Law Review 289-320.

Lazare, A. 2004. On Apology. New York: Oxford University Press.

Leunissen, J.M., D. De Cremer, C.P. Reinders Folmer, and M. Van Dijke. 2013. “The Apology Mismatch: Asymmetries between Victim's Need for Apologies and Perpetrator's Willingness to Apologize," 49 Journal of Experimental Social Psychology 315-324.

Leunissen, J.M., D. De Cremer, M. Van Dijke, and C. Reinders Folmer. 2014. "Forecasting Errors in the Averseness of Apologizing," 27 Social Justice Research 322-339.

Levi, D.L. 1997. "The Role of Apology in Mediation," 72 New York University Law Review 1165-1210.

Lewicki, R.J., B. Polin, and R.B. Lount. 2016. "An Exploration of the Structure of Effective Apologies," 9 Negotiation and Conflict Management Research 177-196.

Loewenstein, G., S. Issacharoff, C. Camerer, and L. Babcock. 1993. "Self-Serving Assessments of Fairness and Pretrial Bargaining," 22 Journal of Legal Studies 135-159. 
Malle, B.F. 2006. "The Actor-Observer Asymmetry in Attribution: A (Surprising) Meta-Analysis," 132 Psychological Bulletin 895-919.

Okimoto, T. G., and T. R. Tyler. 2007. "Is Compensation Enough? Relational Concerns in Responding to Unintended Inequity," 10 Group Processes \& Intergroup Relations 399-420.

Peer, E., L. Brandimarte, S. Samat, and A. Acquisti. 2017. "Beyond the Turk: Alternative Platforms for Crowdsourcing Behavioral Research," 70 Journal of Experimental Social Psychology 153-163.

Rachlinski, J.J., C. Guthrie, and A.J. Wistrich. 2013. "Contrition in the Courtroom: Do Apologies Affect Adjudication?," 98 Cornell Law Review 1198-1243.

Relis, T. 2007. "It's Not about the Money! A Theory on Misconceptions of Plaintiffs' Litigation Aims," 68 University of Pittsburgh Law Review 341-385.

Riek, B.M. 2010. "Transgressions, Guilt, and Forgiveness: A Model of Seeking Forgiveness," 38 Journal of Psychology and Theology 246-254.

Robbennolt, J.K. 2003. “Apologies and Legal Settlement: An Empirical Examination,” 102 Michigan Law Review 460.

Robbennolt, J.K. 2006. "Apologies and Settlement Levers," 3 Journal of Empirical Legal Studies 333-373.

Rosseel, Y. 2012. “lavaan: An R package for structural equation modeling." 48 Journal of Statistical Software 1-36. doi: 10.18637/jss.v048.i02.

Scher, S. J., and J. M. Darley. 1997. "How Effective are the Things People Say to Apologize? Effects of the Realization of the Apology Speech Act," 26 Journal of Psycholinguistic Research 127-140.

Schumann, K. 2014. "An Affirmed Self and a Better Apology: The Effect of Self-Affirmation On transgressors' Responses to Victims," 54 Journal of Experimental Social Psychology 89-96.

Sherman, L.W., H. Strang, C. Angel, D. Woods, G.C. Barnes, S. Bennett, and N. Inkpen. 2005. "Effects of Face-To-Face Restorative Justice on Victims of Crime in Four Randomized Controlled Trials," 1 Journal of Experimental Criminology 367-395.

Shuman, D.W. 2000. "The Role of Apology in Tort Law," 83 Judicature 180-189.

Stillwell, A.M., and R.F. Baumeister. 1997. "The Construction of Victim and Perpetrator Memories: Accuracy and Distortion in Role-Based Accounts," 23 Personality and Social Psychology Bulletin 1157-1172.

Struthers, C.W., J. Eaton, A.G. Santelli, and M. Uchiyama. 2008. "The Effects of Attributions of Intent and Apology on Forgiveness: When Saying Sorry May Not Help the Story," 44 Journal of Experimental Social Psychology 983-992.

Taft, L. 2005. “On Bended Knee (With Fingers Crossed)," 55 DePaul Law Review 601-616.

Tavuchis, N. 1991. Mea Culpa: A Sociology of Apology and Reconciliation. Stanford: Stanford University Press.

Van Dijck, G. 2018a. "Victim Oriented Tort Law in Action: An Empirical Examination of Catholic Church Sexual Abuse Cases," 15 Journal of Empirical Legal Studies 126-164.

Van Dijck, G. (2018b). “I Am Sorry' (And Therefore Liable)”. On the detrimental effect of nonmonetary relief in tort law and compensation schemes," Maastricht Faculty of Law Working Paper No. 2989486, Retrieved from: https://ssrn.com/abstract=2989486.

Vines, P. 2008. "Apologies and Civil Liability in the UK: A View from Elsewhere," 12 Edinburgh Law Review 200-230. 
Vines, P. 2015. "Apologising for Personal Injury in Law: Failing to Take Account of Lessons from Psychology in Blameworthiness and Propensity to Sue," 22 Psychiatry, Psychology and Law 624-634.

Wagatsuma, H., and A. Rosett. 1986. "The Implications of Apology: Law and Culture in Japan and the United States," 20 Law and Society Review 488-492.

White, B.T. 2005. "Say You're Sorry: Court-Ordered Apologies as a Civil Rights Remedy," 91 Cornell Law Review 1261-1269. 